\title{
ART
}

\section{СУРОК, Соч. 52 № 7 (фр. MARMOTTE) ЛЮДВИГА ВАН БЕТХОВЕНА СТИХИ И. В. ГЁТЕ}

\author{
кандидат искусствоведения, профессор, Зильберман Юрий, \\ Киевская муниципальная академия музыки им. Глиэра, Украина
}

DOI: https://doi.org/10.31435/rsglobal_wos/31052019/6504

\section{ARTICLE INFO}

Received: 21 March 2019

Accepted: 15 May 2019

Published: 31 May 2019

\section{KEYWORDS}

song, Marmotte, stroke, methodic, right hand. \begin{abstract}
In his youth Ludvig van Beethoven wrote the song "La Marmotte" on the words of J. W. Goethe. The predominant feeling in it was loneliness. The further Beethovens time drifted away, the more song transcriptions for a solo instrument became. There was a variant of the piece for piano, violin, flute, etc. All novice musicians almost must have played this piece. Author of the article, folowing the path of the song offers a method of studying the piece to beginner violinist.
\end{abstract}

Citation: Зильберман Юрий. (2019) Surok, soch. 52 № 7 (fr. Marmotte) Lyudviga van Bethovena Stihi I. V. Gyote. International Academy Journal Web of Scholar. 5(35). doi: 10.31435/rsglobal_wos/31052019/6504

Copyright: (C) 2019 Зильберман Юрий. This is an open-access article distributed under the terms of the Creative Commons Attribution License (CC BY). The use, distribution or reproduction in other forums is permitted, provided the original author(s) or licensor are credited and that the original publication in this journal is cited, in accordance with accepted academic practice. No use, distribution or reproduction is permitted which does not comply with these terms.

Какой-то звук щемящчий-между строк,

Откуда был он вызван тишиною? Бессмертна жизнь! А музыка - порог Бессмертия! И мой сурок со мною...

Юнна Мориц

Введение. Песню Л. Бетховена "Сурок" знают все. Если не как песню, то как пьесу для начинающих скрипачей, пианистов, флейтистов, валторнистов и др. Конечно, не все знают: кто такие савояры, почему по дорогам Германии и Франции бродили мальчуганы с дрессированными сурками, показывающими фокусы. Главное, не все до сих пор уверенны, что, укачивая ребенка под колыбельную и напевая ему: «По дальним странам я бродил А ве ке ля мармозе. И сыт всегда, весел я был. А ве ке ля мармозе», они поют великого Л. Бетховена!

Пьеса же, пустившись в путь по векам и инструментам, обязательно звучит зимой и летом на экзаменах и академических концертах в музыкальных школах. Особенно часто ее играют скрипачи, т.к. тональность (ля минор), краткость мелодии (6 нот), а главное, игра на средних струнах (ля и ре), делают эту пьесу фантастически удобной на начальной стадии обучения. И редко, кто из учеников, и даже их учителей задумывается над сложностью пьесы для руки, ведущей смычок. В статье предлагается графически представить движение смычка во время игры этой пьесы.

В творчестве Людвига ван Бетховена нашли воплощение все жанры конца XVIII начала XIX века: симфонии, концерты, сонаты для различных инструментов, квартеты, фантазии, увертюры, мессы, вариации, багатели, экосезы, вальсы, произведения для фортепиано в 4 руки, ораториальные произведения, опера, камерные сочинения, даже сочинения для духового оркестра. Особое место занимают песни. Их не много (около 80, точнее - 79 по подсчетам Ганса Боетчера - единственного музыковеда, кто рискнул описать их в книге "Л. Бетховен, как песенный композитор" [1]), но они пронизывают всю жизнь композитора - от ранней молодости до смерти. К песням Л. Бетховена особое отношение: цикл "К далекой возлюбленной" (Круг песен, стихи Алоиза Эйтелеса) заслоняет собой все! До этого были песни на стихи многих немецких поэтов: G.A. Bürger, F. Matthisson, G.A. von Halem, C.F. Gellert, S.F. Sauter, St. Von Breining, Crhr, L. Reißig, J.L. Stoll, F.R. Hermann, C. Lappe, F.A. Kleinschmidt, 
J.H. Herder, F.G. Klopstock, наконец, J.W. Goete! В самом начале своего пути, Л. Бетховен написал песню "La Marmotte" (Сурок) на стихи Иоганна Вольфганга Гетте.

Эдуард Эрио, один из наиболее известных биографов композитора так писал о начальном периоде творчества Людвига ван Бетховена: "Все же начальный период творческой жсизи Бетховена до сих пор еще остается в какой-то своей части плохо известным. Достоверно лишь то, что с душой, переполненной музыкальныли замыслами, он набирается опыта, сочиняя вариачии, сонаты ${ }^{1}$; что, при всех осознанных влияниях или неосознанных воздействиях, им испытанных, индивидуальность его проявляется в стремлении к мелодии, в подчеркнутой склонности к выразительности, в столь ощутимой во всем последующем творчестве смене настроений печали и радости, в искренности еще сдержанной патетики" [6, 15].

Л. Бетховен написал музыку к стихотворению И.В. Гете в 1782 году, то есть на восемь лет позже появления стихов в качестве песенки к спектаклю "Ярмарка в Плундершвайлере" (Jahrmarkt in Plunderschweiler) [5]. (1774 +8 =1782). Очень трудно установить точную дату публикации песни. В различных источниках указан 1790, 1795, 1800, даже 1805 годы, но документального подтверждения этому факту - автор не нашел. Единственное неопровержимо: Л.Бетховен проставил песне "Сурок" ор.52, что подтверждает версию о том, что песня опубликована через несколько лет после ее создания. Издана же она в числе 8 песен под №7. В ней есть грусть - написана в ля миноре, да и слова "по дальним странам я бродил...". Есть элемент веселья: припев - "девиц веселых я встречал..." Все это не исключает ощущения тоски и одиночества, которое молодой автор вкладывает в спокойную мелодию, поддерживаемую "колышущимся", как бы триольным, аккомпанементом.

$\mathrm{He}$ думаю, что историю бродячих швейцарских мальчиков (юношей) с дрессированными сурками (иногда с шарманками, иногда - без) не знают ${ }^{2}$. Ничего особенного в ней нет: ходили, бродили по Германии (страна считалась "сытной") юноши, мальчики из бедной Швейцарии, показывали всякие фокусы с помощью специально ими дрессированных маленьких зверьков (в основном, сурков, т.к. зверек не большой, довольно хорошо выполняет команды). Выступления часто сопровождались пением под шарманку. Насчет шарманки, скорее всего, авторы, пишущие о савоярах заблуждались: все-таки 15 кг. - вряд ли мог носить с собой мальчик 9-10 лет (на картинах художников XIX в. Василия Перова, Константина Маковского изображены 9-10-летние мальчуганы, очень бедные и несчастные.

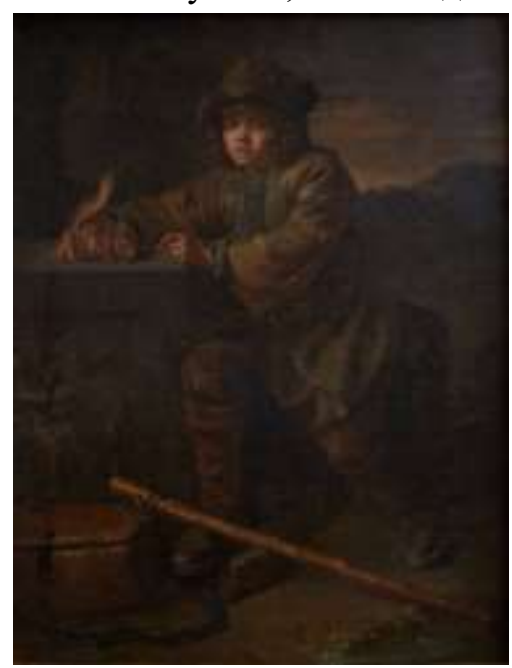

\footnotetext{
1 Добавим: песни.

${ }^{2}$ Савоя́р, савоя́ры (фр. Savoyard) - в прямом смысле слова - жители Савойи, современного региона Франции - или исторического княжества, государства на территории современной Франции, Италии и Швейцарии. В более узком смысле - бродячие певцы (из Савойи), странствующие по дорогам Франции, в средние века примерно то же, что мейстерзингеры, труверы или трубадуры, а позднее - обнищавшие жители Савойи, зачастую - крестьянские дети, ходившие по дорогам Франции и просившие милостыню своими песнями (иногда с сопровождением шарманкой и учёным сурком). https://ru.wikiquote.org/wiki/\%D0\%A1\%D0\%B0\%D0\%B2\%D0\%BE\%D1\%8F\%D1\%80

Добавим, что савояр - это не всегда "мальчик с сурком". Савояры - дети-пастухи, которые пасли стадо. Но в голодные годы, отцы - жители Савойи, действительно отсылали своих детей странствовать по сытой Германии. Собственно их-то и называли немцы Savoyahr. Василий Перов изобразил спящего савояра (картина 1863 г. "Савояр") совершенным ребенком (мальчику - лет 9-10). У А.Ватто "Савояр" значительно старше, думается, что именно таким, более старшим по возрасту, было под силу передвигаться с шарманкой.
} 
И только у французского художника XVIII Антуана Ватто (А.Ватто) савояр улыбающийся молодой человек (лет 13-15) на фоне светлого синего неба, который в состоянии поднять шарманку).

О сурке в изданиях, посвященных жизни животных написано:

"Очень напоминает жизнь людей: точно также есть мама, папа, братья, сестренки. Когда приходит весна, маленькие дети сурков играют друг с другом, борются, бегают друг за другом. Мама обязательно сидит у норы и смотрит, чтобы они сильно не подрались, не съели друг друга, в нужный момент заставляет их спрятаться в нору. Сначала папа никакого участия в воспитании детей не принимает. Потом, когда детеныши подрастают, папа возвращается в основную нору и начинает заниматься детьми. Они пасутся вместе, играют." [7].

В популярном блоге Ханны Таупекки (она даже свои публикации обозначает так: Сурок по вторникам с Ханной Таупекка № 1 [8], думаю, есть №№2,3,4 и т.д.) интересная мысль о сурках и песне Л.Бетховена: Едва ли хоть какой безвинной зверушке во всей музыкальной истории икалось так нещадно, как бедолаге сурку: опрос друзей-музыкантов показал, что, помимо скрипачей, его играли начинающие пианисты, флейтисты, гитаристь, его пели на сольфеджио все, кому не довелось сыграть, и даже страшно далекий от академических изысков человек с хоромей вероятностью узнает начальные такты мелодии, если и не вспомнит слов.

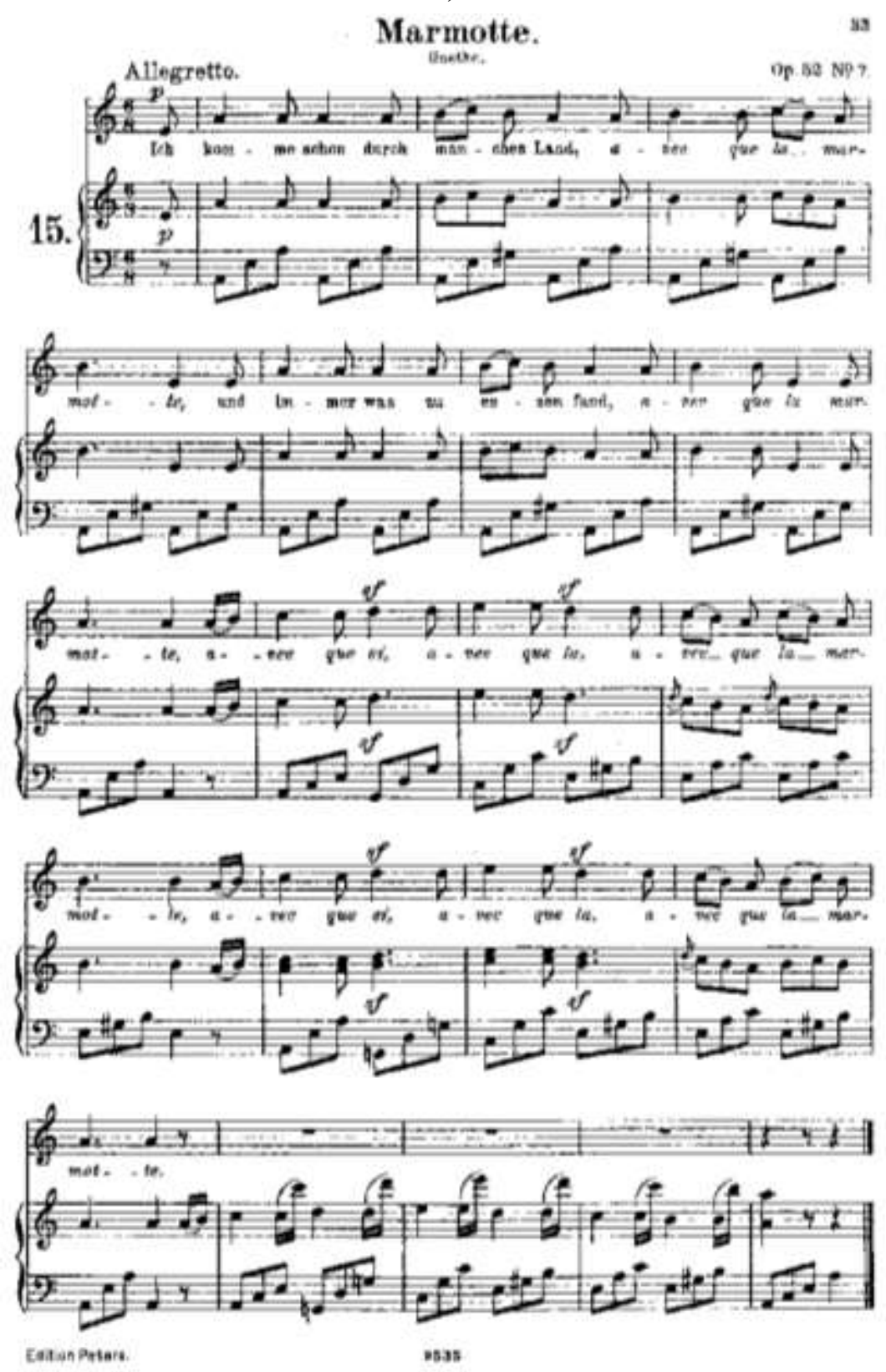

Puc. 1. 
Сама пьеса И.В.Гете "Ярмарка в Плундершвайлере" (Jahrmarkt in Plunderschweiler) - это, скорее, пародия на типичные ярмарочные представления 18 в.: в ней масса типично ярмарочных героев Зазывала, Гансвурст, Судебный пристав, Доктор, Тиролец, Нюрнбержец, Гувернантка, Цыганский капитан, Барышня и т.п. Сам И.В.Гете, участвуя в постановке, избрал для себя роль Зазывалы. В пьесе он высмеивает порядки немецких городов (среди героев пьесы есть фермер, которому безразлично качество: лишь бы крейцер попал в его карман, строитель, предлагающий покупать необыкновенную дрянь, но за полцены), быта и развлечений простого народа. В этом удивительном спектакле-пародии, находится место и для священного гнева:

(Glaube mehr an keine Gott Ist es ein Schand und Spott),

и насмешки над "рыцарями" и "дамами"

(Wie sie zusammen kamen

Sich begehn, sich begatten

In alle grüne Schatten

Uf alle grüne Heide),

и уничижения: (Wenn wir heut Abend auf allen Vieren

Das liebe Publikum amüsieren),

и удивительных "попаданий" молодого автора в сегодняшний день

(Jeder Tag seine eigne Plage hat).

Может быть, как бы оттеняя их, так трогательна песня Савояра, написанная Гете для пьесы.

Хотелось бы отметить, что "Сурок", претерпев множество переложений для различных инструментов, стал использоваться в начале обучения музыканта: очень "удобная" мелодия (в ней всего 6 нот) и размеренный аккомпанемент пьесы. Те, кто играет пьесу, даже не задумываются над грустными словами И.В.Гете, играя лишь мелодию. Через много лет (1823) Франц Шуберт напишет знаменитую песню "Мельник и ручей" (Der Müler und der Bach), в которой монолог Мельника, правда, в соль миноре - столь же грустный. Тексты песен несравнимы, ибо у Ф.Шуберта обращение к ручью символично (но и пользуется-то он намного большим набором красок: 2-я "низкая" минора, сопоставление минора и мажора, подражание ручью в партии фортепиано) прощание с жизнью. Заметим, что оба гения писали свою музыку примерно в одном возрасте, но разница во времени (около 40 лет) сделала возможным Ф.Шуберту писать диалог самоубийцы с ручьем, Л.Бетховену же -, неприкаянность скитания и одиночество мальчишки-савояра. Нам кажется, что рассказать о содержании песен учитель должен во чтобы это ни стало! Наверное, возраст "исполнителя" - юн. Почти наверняка, все красноречие учителя не создаст того "настроения образа", которое вложено композитором... Но, этот рассказ должен подтолкнуть юного исполнителя к мысли о необходимости вникать в содержание сочинения, читать все о композиторе, все, что так или иначе, относится к музыке этого сочинения...

Почти все мальчики и девочки, учившиеся в музыкальных школах, играли эту пьеску, не зная слов и не особенно вникая в ее содержание, так как за двести пятьдесят лет, что отделяет нас от ее написания, песня "La Mormotte" была переложена для исполнения на: флейте, гобое, кларнете, фаготе, валторне, скрипке, фортепиано, трубе, тромбоне, виолончели, то есть почти для всех инструментов симфонического оркестра. Думается, что любой, проходивший курс музыкальной школы, вне зависимости от инструмента на котором он играл, сможет сказать, что на первом или втором году обучения играл "Сурок" Л.Бетховена. Сложность для юных скрипачей обусловлена довольно интенсивной работой правой руки, держащей смычок.

Размер 6/8 идеально подходит маленькому скрипачу, т.к. правая рука еще малоопытного исполнителя, естественно, в движении вниз всегда будет сильнее, что нормально, то есть, четверть (или залигованные две "восьмушки") - в движении вниз и восьмая - в движении вверх). В начале припева есть сложность для маленького скрипача: две "шестнадцатые", которые нужно сыграть вместо одной "восьмой": "ля" "си", причем в движении смычка вверх. Если представить себе графически, то возникает вопрос к скрипачу: вниз четверть с точкой и еще четверть залигованная "си"(5 восьмых), вверх смычком, нужно сыграть четверть "ми", и в конце ведения смычка вверх - эти две шестнадцатые - "ля" "си"

$\mathrm{c}$

И (5 восьмых) "вниз"

ля, си_(2 шестнадцатых) "вверх" 


\section{CVPOK}
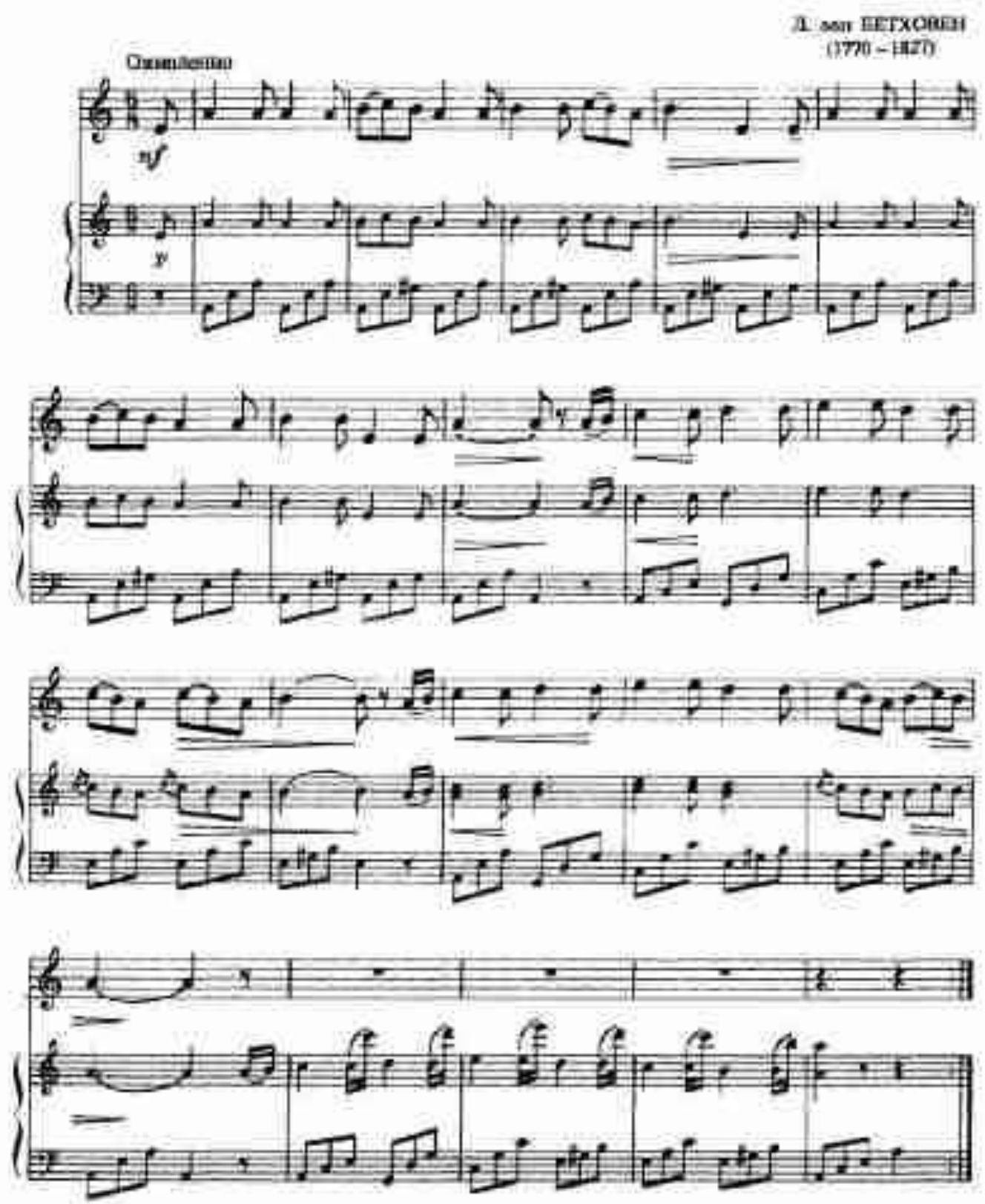

Puc. 2.

Впрочем, кроме того, что левая рука должна ставить пальчики так, чтобы интонационная чистота была безукоризненной, основная нагрузка этой пьесы и состоит в точном и выверенном движении смычка. То есть, фактически, именно правая рука (движение смычка) играет главную роль. Струны "ре" и "ля", хоть и"средние" ("соль" и "ми" - крайние), но занимают на скрипке более высокое положение благодаря полукруглой подставке и смычок, если держать его строго горизонтально, всегда будет на этих струнах. - Пожалуй, - это первое.

Существует два положения второго пальца левой руки: первый - это второй палец почти вплотную прижат к третьему, тогда на струне "соль" - это звук $\boldsymbol{C}$, на струне "ре" - это ФА-ДИЕ 3, струна "ля" - ДО-ДИЕЗ, струна "ми" - СОЛЬ-ДИЕЗ. Понятно, что для ля минора, в котором написан "Сурок", необходима другая расстановка пальцев. Если поставить второй палец вплотную к первому пальцу, то звуки будут другими: на струне "соль" - CИ-БЕМОЛЬ, струне "pe" - ФА, струне "ля" - ДО и струне "ми" - СОЛЬ. То есть, бетховенская тональность ля 
минор подходит для второго положения, ведь почти вся пьеса звучит на струне "ля" и второй палец, в таком случае, вплотную к первому, прижимает ноту "До".

Пожалуй, именно движение смычка, то есть движение правой руки, является самой большой сложностью этой пьесы. Нам кажется, что сделав с учеником не сложную схему ведения смычка (естественно, чтобы ученик сам составлял-рисовал ее), можно добиться значительного ускорения процесса подготовки разучивания пьесы.

Представим себе ситуацию, когда маленький(ая) скрипач(ка) выполняет задание учителя - рисует на бумаге горизонтальные линии, надписывая на них ноты пьесы:

\section{Движение смычка пьесы Л.Бетховена "Сурок"}

вверх

ми (восьмая)

вниз ля (четверть с точкой)

вверх ля (восьмая)

вниз ля (четверть с точкой)

вверх ля (восьмая)

вниз си, до (восьмые)

вверх си (восьмая)

вниз ля (четверть)

вверх ля (восьмая)

вниз си (четверть)

вверх си (восьмая)

вниз до, си (восьмые)

вверх ля (восьмая)

вниз си (четверть с точкой и еще четверть залигованная)

вверх ми_(восьмая) повтор 2-я строчка

вверх ля, си (шестнадцатые)

вниз до (четверть)

вверх до (восьмая)

вниз ре (четверть)

вверх pe (восьмая)

вниз ми (четверть)

вверх ми (восьмая)

вниз ре (четверть)

вверх pe (восьмая)

вниз до, си (восьмые)

вверх ля (восьмая)

вниз до, си (восьмые)

вверх ля (восьмая) 
вниз си (четверть с точкой и еще четверть, залигованная)

вверх ля, си (шестнадцатые)

вниз до (четверть)

вверх до (восьмая)

вниз ре (четверть)

вверх ре (восьмая)

вниз ми (четверть)

вверх ми (восьмая)

вниз ре (четверть)

вверх ре (восьмая)

вниз до, си (восьмые)

вверх ля (восьмая)

вниз си, до (восьмые)

вверх си (восьмая)

вверх ля (четверть с точкой, лига- четверть)

Конечно, это не является "панацеей", но надежда на то, что ребенок, в процессе "рисования", начнет осознавать - есть.

Выводы: 1. В песне "Сурок" Л.Бетховен предстает перед нами, как композитор, сумевший в столь короткой, несложной мелодии (6 звуков), передать чувства острой щемящей тоски и одиночества. 2. Пьеса за 250 лет (без текста) превратилась в одно из самых популярных музыкальных сочинений почти для всех инструментов симфонического оркестра. 3. Для юных исполнителей-скрипачей пьеса представляет значительную сложность только для руки, ведущей смычок. 4. Осознанию этой сложности можно способствовать, предложив молодому(й) скрипачу(чке) методику графического изображения ведения смычка.

\section{ЛИТЕРАТУРА}

1. Boettcher H. Beethoven als Liederkomponist. Printed in Germany. Copirigth 1928 by Benno Fischer Vertag G.m.b.H, Augsburg. S. - 192.

2. Драматургия Ярмарки в Плундерсвейлерне Электронный ресурс. Обращение: 19.05.2019 http://gete.velchel.ru/index.php?cnt=13\&sub=14\&page=9

3. Сурок по вторникам с Ханной Таупекка № 1 Электронный ресурс. Обращение: 22.05.2019 http://ezhe.ru/ib/issue772.html.

4. Савояр. Электронный ресурс. Обращение: 18.05 .2019 https://ru.wikiquote.org/wiki/\%D0\%A1\%D0\%B0 $\% \mathrm{D} 0 \% \mathrm{~B} 2 \% \mathrm{D} 0 \% \mathrm{BE} \% \mathrm{D} 1 \% 8 \mathrm{~F} \% \mathrm{D} 1 \% 80$

5. Johann Wolfgang von Goethe: Jahrmarktsfest zu Plundersweilern. Электронный ресурс. Обращение: 24.05.2019. https://gutenberg.spiegel.de/buch/jahrmarktsfest-zu-plundersweilern-3678/1

6. Erio E. Beethovens Leben Retrieved from: https://libking.ru/books/nonf-/nonf-biography/480478-15eduard-errio-zhizn-bethovena.html\#book

7. Электронный ресурс. Обращение: 22.05.2019 http://bobak.ru/category/vidy-surkov

8. Электронный ресурс. Обращение 23.05.2019 http://ezhe.ru/ib/issue772.html 